\title{
A Non-Dimensional Consideration in Combustor Axial Stress Computations
}

\author{
Ebene Ufot ${ }^{1,2}$, Barinaadaa Thaddeus Lebele-Alawa $^{{ }^{*}}$, Ibiba Emmanuel Douglas ${ }^{1}$, Kelvin D. H. Bob-Manuel ${ }^{1}$ \\ ${ }^{1}$ Faculty of Engineering, Rivers State University of Science and Technology, Port Harcourt, Nigeria \\ ${ }^{2}$ Department of Mechanical Engineering, University of Uyo, Uyo, Nigeria \\ E-mail: lebele-alawa.thaddeus@ust.edu.ng \\ Received June 23, 2010; revised August 5, 2010; accepted August 5, 2010
}

\begin{abstract}
Thermal stresses in the combustor of gas-turbines are computed using non-dimensional parameters. Buckingham pi theorem was used to arrange the listed relevant parameters into non-dimensional groups. In testing the validity of the functional relation of the non-dimensional independent parameters, use is made of the prevailing temperatures of the combustor in operation. A computer program was used to enhance computations. The results showed an interesting way of influencing the axial stresses. To reduce stresses in gas-turbine combustors, a method of varying the independent parameter that is of radius ratio oriented and thickness dependent was adopted. This showed a reduction of the axial stresses to minimal levels using the parameters. Plots were made and a point of inflection that manifested itself in the presentation of the axial stress function was further investigated upon. It turned out to be a point of abnormal stress level and out-of-trend temperature profile. The use of non-dimensional consideration proved adequate in the computation of axial stresses. The results showed a 2 percent difference from existing values of stresses got from a transient thermal loading of a combustor.
\end{abstract}

Keywords: Thermal, Stresses, Combustor, Gas-Turbine

\section{Introduction}

Thermally induced axial stresses or shocks occur in materials when they are heated or cooled. It affects the operations of gas-turbines due to the large components subjected to stresses. Many structural elements of hollow cylinders subjected to rapid internal heating crack or deform due to thermally induced axial stresses produced in them. Tret'yachenko, et al. [1] carried out investigations on thermal stresses of hollow cylinders drum of unilateral internal heating. The main aim of their investigations was to obtain graphs that could be used to estimate the stress level in cylindrical structural elements. Kumar and Rajgopalan, [2] performed non-dimensional stress analysis on cylindrical objects. They obtained plots of non-dimensional tangential stress against non-dimensional length of cylinder. Their presentations showed the differences in the values of functions from various radial positions.

The analytical solution for computing the radial and circumferential stresses in a functionally graded material (FGM) thick cylindrical vessel under influence of inter- nal pressure and temperature was presented by Abrinia et al. [3]. FGMs are fabricated by continuously changing the volume fraction of two basic materials (usually ceramics and metals) in one or more directions.

\begin{tabular}{|c|c|}
\hline Nomenclatu & \\
\hline Ax.Str.Funct & Axial stress function $-\sigma_{z t h} / E$ \\
\hline $\mathrm{C}$ & $\begin{array}{l}\text { Non-dimensional axial stress parameter } \\
\text { for average temperature }\end{array}$ \\
\hline $\mathrm{C}_{1}$ & $\begin{array}{l}\text { Non-dimensional axial stress parameter } \\
\text { as ratio of radius dependent }\end{array}$ \\
\hline $\mathrm{C}_{2}$ & $\begin{array}{l}\text { Non-dimensional axial stress parameter } \\
\text { as ratio of temperature to } \\
\text { average temperature }\end{array}$ \\
\hline $\mathrm{E}$ & Young's modulus of elasticity \\
\hline $\mathrm{T}$ & Temperature in Kelvin \\
\hline $\mathrm{T}_{\mathrm{i}}$ & $\begin{array}{l}\text { Temperature of the bulk airstream of } \\
\text { combustion products }\end{array}$ \\
\hline $\mathrm{T}_{\mathrm{m}}$ & Average temperature in combustor \\
\hline $\mathrm{T}_{\mathrm{ma}}$ & $\begin{array}{l}\text { Maximum average temperature in com- } \\
\text { bustor }\end{array}$ \\
\hline
\end{tabular}




\begin{tabular}{|ll|}
\hline $\mathrm{T}_{\text {wa }}$ & Combustor outer wall temperature \\
$\mathrm{T}_{\text {wi }}$ & Combustor internal wall temperature \\
$\mathrm{T}_{\text {surr }}$ & Temperature of the surroundings \\
$\mathrm{r}$ & Radial distance from centre of cylinder \\
$\mathrm{r}_{\mathrm{a}}$ & Radius to outer wall \\
$\mathrm{r}_{\mathrm{i}}$ & Radius to inner wall \\
& \\
Greek letters & \\
$\alpha$ & Coefficient of thermal expansion \\
$\sigma$ & Axial stress \\
$v$ & Poisson's ratio \\
& \\
Suffixes & \\
$\mathrm{r}$ & radial stress \\
$\varphi$ & tangential stress \\
$\mathrm{zth}$ & Thermal stress in axial $(\mathrm{z})$ direction \\
\hline
\end{tabular}

In the analysis, the effect of non-homogeneity in FGM thick cylinder could be implemented by choosing a dimensionless parameter, $\beta$, which could be assigned an arbitrary value affecting the stresses in the cylinder. Various values of $\beta$ were used to demonstrate the effect of in-homogeneity on the stress distribution. They concluded that by changing the values of $\beta$, the properties of FGM could be so modified that the lowest stress levels were reached.

Kubo et al. [4] investigated a multidisciplinary problem of heat conduction, elastic deformation, heat transfer, liquid flow. They used inverse method for determining the optimum thermal load history which reduced transient thermal stress. Temperature history functions were introduced to ensure the continuity of the temperature increasing rate. The multidisciplinary complex problem was decomposed into heat transfer and thermal stress problems. Ootoa et al. [5] determined the temperature and thermal stress distribution in the cross-section of a non-homogenous hollow circular cylinder due to a moving heat source in the axial direction, and found that; the maximum temperature occurs at the region through which the moving heat source passed. All of the above used non-dimensional functions of stress and found that it very conveniently influenced the stresses so computed. Principal axes that could be considered in thermal stresses in hollow cylinders are axial, radial and the tangential. In this work only axial stresses will be considered. A non-dimensional approach of expression of the pertinent parameters has been adopted. This makes the expressions more compact and allows a wider understanding of the properties in further considerations. Dimensional analysis using the Buckingham $\pi$ theorem has been applied in analyzing the stress problems. This therefore presents the axial stresses in few independent non-dimensional parameters. Thus it has enhanced the establishment of influencing factors to reduce stresses in materials. The involvement of a computer code has enabled fast computation of the axial stresses.

\section{Materials and Methods}

From the equation of thermally induced axial stress [6] one can re-work it to the required expression

$$
\text { Axial Stress, } \sigma_{\mathrm{zth}}=v\left(\sigma_{\mathrm{rth}}+\sigma_{\varphi \mathrm{th}}\right)-\mathrm{E} \alpha_{\mathrm{th}} \mathrm{T}(\mathrm{r})
$$

where $\sigma_{\mathrm{rth}}$ and $\sigma_{\text {tth }}$ are given as:

Radial Stress,

$$
\begin{aligned}
& \sigma_{r t h} \\
& =\frac{E \alpha_{t h}}{1-v}\left[\frac{r^{2}-r_{i}{ }^{2}}{r_{a}{ }^{2}-r_{i}{ }^{2}} \frac{r_{a}{ }^{2}}{r^{2}} T_{m}(r a)-T_{m}(r)\right]
\end{aligned}
$$

Tangential Stress,

$$
\begin{aligned}
& \sigma_{\phi t h} \\
& =\frac{E \alpha_{t h}}{1-v}\left[\left[\frac{r^{2}+r^{i^{2}}}{r_{a}{ }^{2}-r^{i^{2}}}\right] \frac{r_{a}^{2}}{r^{2}} T_{m}(r a)+T_{m}(r)-T(r)\right]
\end{aligned}
$$

Turning Axial Stress Equation to a Non-Dimensional Equation:

From Equation (1) above,

$$
\sigma_{z t h}=v\left(\sigma_{r}+\sigma_{\phi}\right)-E \alpha_{t h} T(r)
$$

$$
\begin{aligned}
\sigma_{z t h} & =v * \frac{E \alpha_{t h}}{1-v}\left[\frac{r^{2}-r_{1}^{2}}{r_{a}^{2}-r_{1}^{2}} *\left[\frac{r_{a}}{r}\right]^{2} * T_{m a}-T_{m}(r)+\frac{r^{2}+r_{i}^{2}}{r_{a}^{2}-r_{i}^{2}}+\left[\frac{r a}{r}\right]^{2} * T_{m a}+T_{m(r)}-T_{(r)}\right]-E a_{t h} T_{m} \\
& =\frac{v E \alpha_{t h}}{1-v}\left[\frac{r 2-r_{i}^{2}}{r_{a}^{2}-r_{i}^{2}} *\left[\frac{r_{a}}{\tau}\right]^{2} * T_{m a}+\frac{r+r_{i}^{2}}{r_{a}^{2}-r_{i}^{2}} *\left[\frac{r a}{r}\right] * T_{m a}-T_{(r)}\right]-E \alpha_{t h} T_{(r)} \\
& =\frac{v E \alpha_{t h}}{1-v}\left[\frac{1}{r_{a}^{2}-r_{i}^{2}} * \frac{r_{a}^{2}}{r^{2}}+T_{m a} * 2 r^{2}-T_{(r)}\right]-E \alpha_{t h} T_{(r)} \\
& =\frac{v E \alpha_{t h}}{1-v}\left[\frac{1}{r_{a}^{2}-r_{i}^{2}} *\left[\frac{r a}{r}\right]^{2} * T_{m a} x\left(r^{2}-r_{i}^{2}+r^{2}+r_{i}^{2}\right)-T_{(r)}\right]-E \alpha_{t h} T_{(r)}
\end{aligned}
$$




$$
\begin{gathered}
=\frac{2 v E \alpha_{t h}}{1-v} \frac{T_{m a}}{\left[1-\left(\frac{r i}{r a}\right)^{2}\right]}-\frac{E \alpha_{t h}}{1-v} T_{(r)} \\
\sigma_{z t h}=\frac{E \alpha_{t h}}{1-v} * T_{m a}\left(\frac{2 v}{1-\left(\frac{r i}{r a}\right)^{2}}-\frac{T_{(r)}}{T_{m a}}\right)
\end{gathered}
$$

Hence, from Equation (2) above, some functional relation must exist in the form of

$$
\sigma_{\text {Zth }}=\sigma_{\text {Zth }}\left(E, \quad \alpha_{t h}, r_{a}, \quad r_{i}, \quad T_{m a}, T_{(r)}\right)
$$

\section{Dimensionless Consideration on Axial Stress.}

Sorting out the inherent parameters:

Forming a table of parameters: Table 1.

The Buckingham $\pi$ theorem proves that in a physical problem including $\mathbf{n}$ quantities in which there are $\mathbf{m}$ dimensions, the quantities can be arranged into $\mathbf{n}-\mathbf{m}$ independent dimensionless parameters.

Hence some functional relation must exist in the form as expressed in Equation (5)

$$
\sigma_{z t h}=\sigma_{z t h}\left(\begin{array}{llllll}
E, & \alpha_{t h} & r_{a}, & r_{i}, & T_{m a}, & T_{(r)}
\end{array}\right)
$$

Applying the Buckingham $\pi$ theorem, there are three $\pi$ groups to be found, so Axial Stress, $\sigma_{z_{t h}}$ can be more compactly stated as a function of these three non-dimensional parameters [7]. Thus from Equation (5)
1. $\frac{\sigma_{z}}{E}-$ as a non-dimensional parameter (Axial Stress Function)

2. $\frac{T_{(r)}}{T_{m a}}-$ as $C_{2}$
3. $\frac{2 v}{1-\left(\frac{r_{i}}{r_{a}}\right)^{2}}$ as $C_{1}$

4. $T_{m a} * \alpha_{t h} /(1-v)$ as $C_{0}$

Actually, the main three independent dimensionless parameters can be seen as:

$$
\sigma_{z} / E, C_{0} * C_{1} \text { and } C_{0} * C_{2}
$$

But Equation (3) can be written as:

$$
\frac{\sigma_{Z t h}}{E}=C_{0} \quad\left[\begin{array}{lllll}
C_{1} & (r) & - & C_{2} & (r)
\end{array}\right]
$$

\section{Results and Discussions}

The results of the non-dimensional axial stress computations are shown as program results below, and the corre-

\begin{tabular}{|c|c|c|c|c|c|c|}
\hline $\begin{array}{l}\text { VarNr, } \\
1\end{array}$ & $\begin{array}{l}\text { ra, } \\
38\end{array}$ & $\begin{array}{c}\text { Twa, } \\
2549.6\end{array}$ & $\begin{array}{c}\text { Twi } \\
2584.1\end{array}$ & & & \\
\hline $\begin{array}{l}\mathrm{T}(0), \\
2549.6\end{array}$ & & $\begin{array}{l}\mathrm{T}(1), \\
2558.2\end{array}$ & $\begin{array}{l}T(2), \\
2566.9\end{array}$ & & $\begin{array}{l}\mathrm{T}(3) \\
2575.5\end{array}$ & $\begin{array}{l}\mathrm{T}(4) \\
2584.1\end{array}$ \\
\hline $\begin{array}{l}\operatorname{Tm}(0), \\
194.8\end{array}$ & & $\begin{array}{l}\operatorname{Tm}(1), \\
176.5\end{array}$ & $\begin{array}{l}\operatorname{Tm}(2) \\
130.2\end{array}$ & $\begin{array}{l}\operatorname{Tm}(3) \\
80.7\end{array}$ & $\begin{array}{l}\operatorname{Tm}(4) \\
27.8\end{array}$ & \\
\hline VarNr & & $\mathrm{C} 1$ & $\mathrm{C} 2$ & $\mathrm{C} 0$ & AxialStress & AxialStressFunct:Ax-Str/E \\
\hline 1 & & 3.96 & 13.09 & 0 & .00 & .000000 \\
\hline 1 & & 3.96 & 13.09 & 0.00345 & -6618.35 & -.031516 \\
\hline 1 & & 3.96 & 13.14 & 0 & .00 & .000000 \\
\hline 1 & & 3.96 & 13.14 & 0.00345 & -6650.44 & -.031669 \\
\hline 1 & & 3.96 & 13.18 & 0 & .00 & .000000 \\
\hline 1 & & 3.96 & 13.18 & 0.00345 & -6682.52 & -.031822 \\
\hline 1 & & 3.96 & 13.22 & 0 & .00 & .000000 \\
\hline 1 & & 3.96 & 13.22 & 0.00345 & -6714.61 & -.031974 \\
\hline 1 & & 3.96 & 13.27 & 0 & .00 & .000000 \\
\hline 1 & & 3.96 & 13.27 & 0.00345 & -6746.69 & -.032127 \\
\hline
\end{tabular}
sponding wall thickness values are given in Table 2 . The non-dimensional consideration gave a wider view of the axial stress. In Figure 1 and Figure 2, the values were plotted against a non-dimensional temperature parameter,

\section{EU402-AXIAL STRESS FUNCTION_PROGRAM RESULTS}




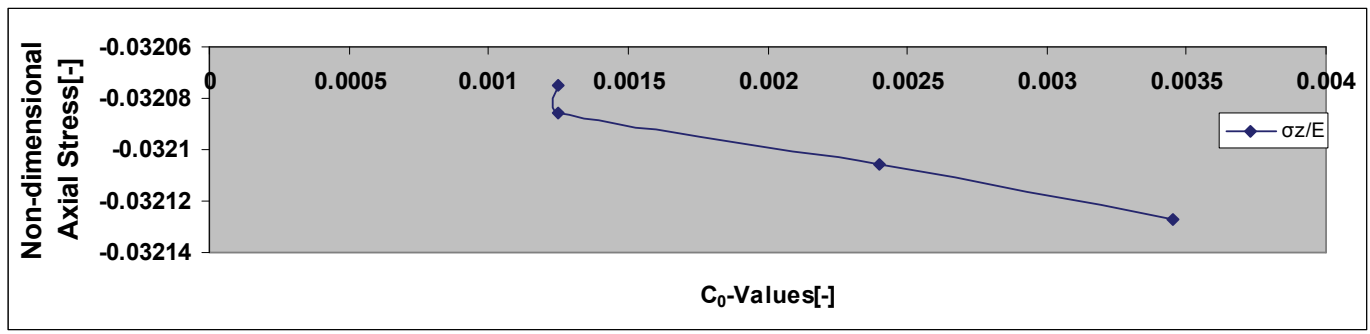

Figure 1. Non-dimensional axial stress versus C0-values.

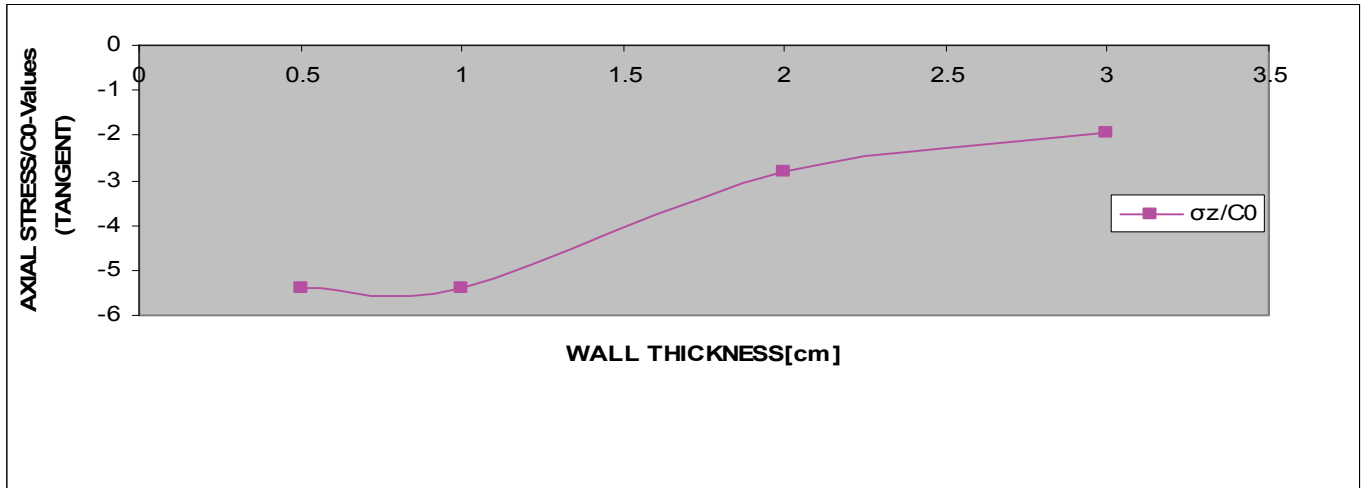

Figure 2. Axial stress/C0 (Tangent) versus wall thickness showing a point of inflection at a thickness of $1.44 \mathrm{~cm}$.

Table 1. Dimensions of independent parameters for axial stress.

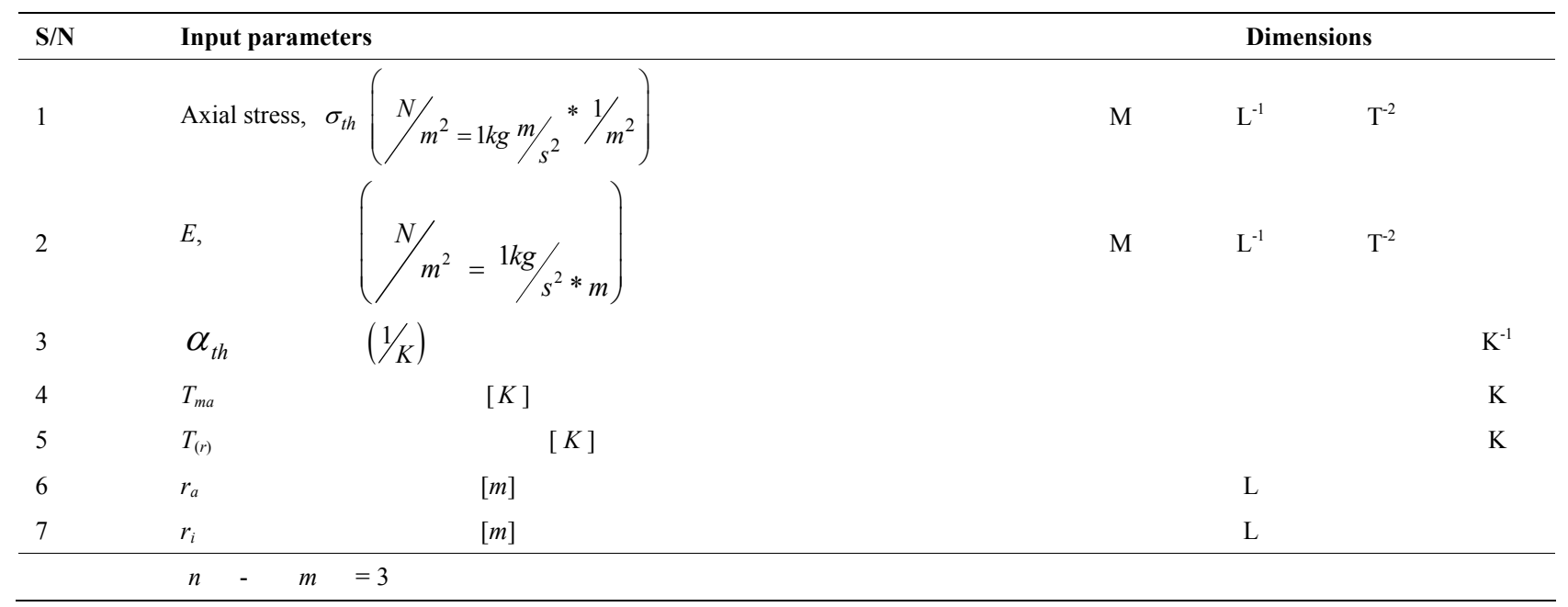

Table 2. Axial stress function versus wall thickness.

\begin{tabular}{lcccccccc}
\hline Var.Nr & $r_{a}$ & $r_{i}$ & $\begin{array}{c}\text { Wall } \\
\text { Thickness }\end{array}$ & $T_{\text {surr }}$ & $T_{i}$ & $T_{\text {wa }}$ & $T_{w i}$ & $\begin{array}{c}\text { Ax.Str.Fct. } \\
\sigma_{\text {zth }}(\mathrm{max})\end{array}$ \\
\hline 1 & 38 & 35 & 3 & 620 & 2620 & 2549.6 & 2584.1 & -0.032127 \\
5 & 37 & 35 & 2 & 620 & 2620 & 2561.9 & 2584.7 & -0.032106 \\
7 & 36 & 35 & 1 & 620 & 2620 & 2574.0 & 2585.4 & -0.032086 \\
10 & 35.5 & 35 & 0.5 & 620 & 2620 & 2580.0 & 2585.7 & -0.032075 \\
18 & 35.25 & 35 & 0.25 & 620 & 2620 & 2586.0 & 2586.5 & -0.032073 \\
16 & 75 & 74.5 & 0.25 & 605 & 2578 & 2535.5 & 2536.0 & -0.031447 \\
(AFAM) & & & & & & & & \\
\hline
\end{tabular}


$\mathrm{C}_{\mathrm{O}}$ and against the wall thickness, respectively. In Figure 3 the axial stress function is plotted against the radial nodal positions. All the presentations show an increasing tendency with increased wall thickness.

The Figure 4 above shows a method of influencing the stress levels in materials:

By increasing the independent parameter, $C_{1}$, the stress levels can be reduced

where

$$
C_{1}=. \frac{2 v}{1-\left(\frac{r_{i}}{r_{a}}\right)^{2}}
$$
ed.

In other words, the radial ratio, $r_{i} / r_{a}$ should be increasIn Equation (4),

$$
\begin{aligned}
& \sigma_{z} / E=C_{0}\left(C_{1}(r)-C_{2}(r)\right) \\
& C_{2} .=\frac{T_{(r)}}{T_{m a}} \\
& C_{1}=\frac{2 v}{1-\left(\frac{r_{i}}{r_{a}}\right)^{2}}
\end{aligned}
$$

And,

$$
C_{0}=. T_{m a} * \alpha_{t h} /(1-v)
$$

If $C_{1}$ is to be high,

Then the ratio $r_{i} / r_{a}$ must be high i.e., $r_{a} \approx r_{i}$

i.e., $r_{a}$ should be reduced to the lowest value applicable.

A table of values can be formed for $r_{i}=35 \mathrm{~cm}$ :

See Table 3, above. The results for internal wall temperatures are presented in Table 4.

Table 3. A non-dimensional parameter, $C 1$ by various ex-

\begin{tabular}{|c|c|c|c|c|}
\hline $\begin{array}{l}\text { Time } \\
\text { [secs] }\end{array}$ & $\begin{array}{l}\boldsymbol{T}_{w i} \\
{[\mathbf{K}]}\end{array}$ & $\begin{array}{l}\text { Axial } S_{\text {tress }} \\
\sigma_{\text {zth }} \\
\text { [MPa] (Ufot, } \\
\text { 2010) }\end{array}$ & $\begin{array}{l}\text { Axial Stress } \\
\text { Function } \\
\left(\sigma_{z t h} / \mathrm{E}\right)[-]\end{array}$ & $\begin{array}{l}\text { Axial Stress } \\
\text { Function } \\
\text { (Present } \\
\text { model) }\end{array}$ \\
\hline 70 & 2027.8 & -5820.0 & -0.027714 & -0.027113 \\
\hline 140 & 2298.2 & -6351.0 & -0.030243 & -0.029990 \\
\hline 210 & 2392.4 & -6531.0 & -0.031100 & -0.031005 \\
\hline 350 & 2429.9 & -6601.0 & -0.031433 & -0.031413 \\
\hline 490 & 2433.0 & -6607.0 & -0.031462 & -0.031447 \\
\hline 630 & 2433.3 & -6608.0 & -0.031467 & -0.031450 \\
\hline 922.1 & 2584.1 & -6746.7 & -0.032127 & -0.032127 \\
\hline
\end{tabular}
ternal wall radius of model.

\begin{tabular}{llll}
\hline $\begin{array}{lll}\boldsymbol{r}_{a} \\
{[\mathbf{c m}]}\end{array}$ & $\boldsymbol{r}_{i} / \boldsymbol{r}_{\boldsymbol{a}}$ & $1-\left(\frac{r_{i}}{r_{a}}\right)^{2}$ & $2 v /\left\{1-\left(\frac{r_{i}}{r_{a}}\right)^{2}\right\}$ \\
\hline 38 & 0.92 & 0.1536 & 3.96 \\
37 & 0.946 & 0.1052 & 5.70 \\
36 & 0.97 & 0.055 & 10.95 \\
35.5 & 0.986 & 0.028 & 21.42 \\
35.25 & 0.993 & 0.014 & 42.86 \\
\hline
\end{tabular}

Table 4. Axial stress function versus internal wall temperatures.

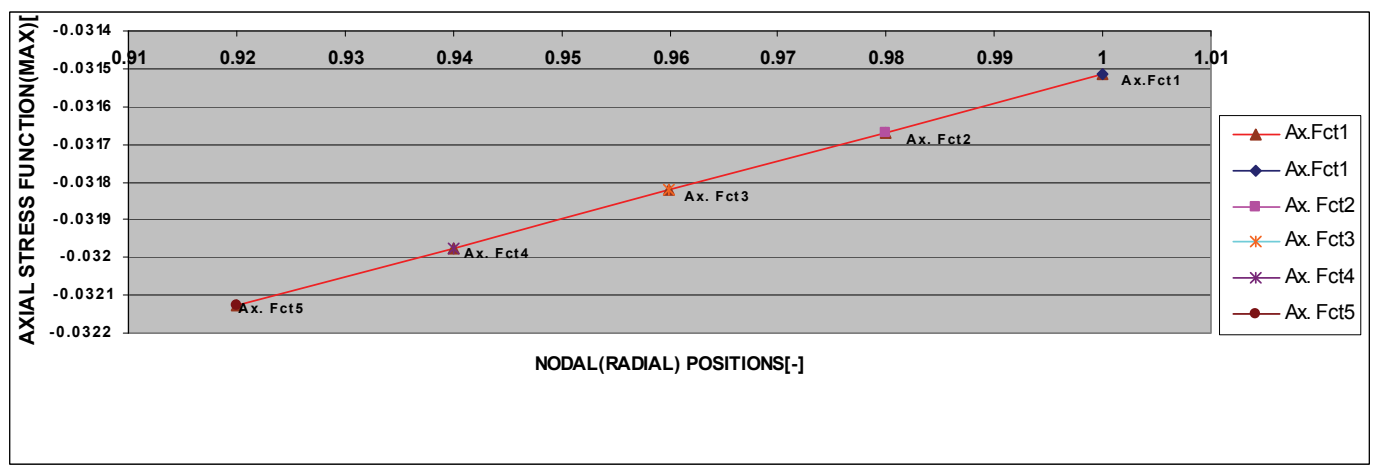

Figure 3. Axial stress function (Max) versus radial nodal positions radial nodal positions $r=r_{i} / r_{a}$.

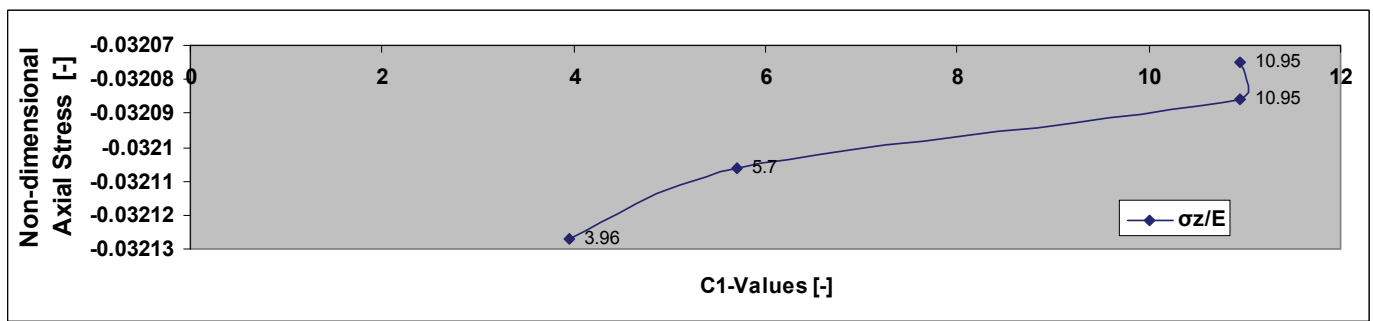

Figure 4. Non-dimensional axial stress versus $C 1$. 


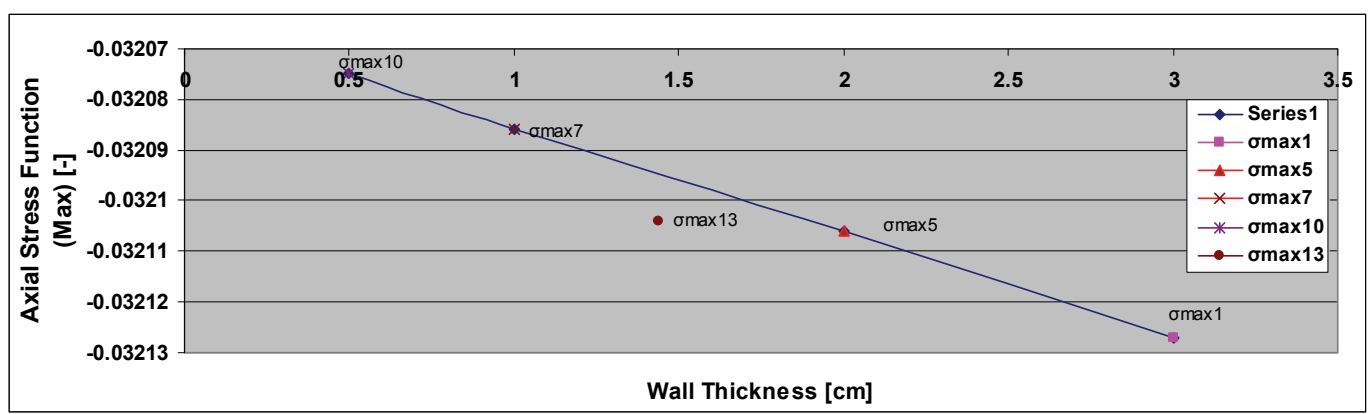

Figure 5. Axial stress function versus wall thickness - showing value position of point of inflection: $\sigma \max 13$.

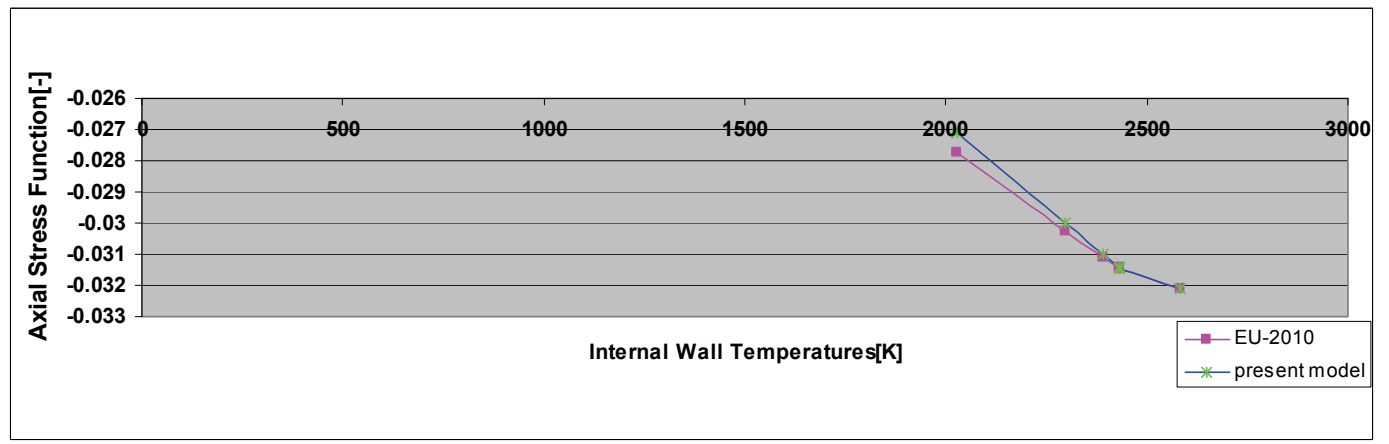

Figure 6. Axial stress function versus internal wall temperatures.

Figure 1 is a presentation of a non-dimensional axial stress against $C_{0}$-values. The non-dimensional temperature parameter, $C_{0}$, is the maximum average temperature dependent parameter. The stress shows a tendency of increasing with the $C_{0}$. That means to reduce the stress in the material, the maximum average temperature in the material must be reduced. And this maximum temperature is noted to be increasing with wall thickness. Therefore, in the final analysis, the wall thickness for minimal thermal stresses should be as small as applicable.

Figure 2 shows a point of Inflection in the presentation of axial stress $/ C_{0}$ with wall thickness. Further consideration of this point of Inflection occurring at a wall thickness of $1.44 \mathrm{~cm}$, shows an abnormal trends of temperatures and stresses in the material. In a cross-sectional view of the non-dimensional stress profile in the material shows linear relationship with the non-dimensional radial positions. In Figure 4, a non-dimensional axial stress is shown varying against $\mathrm{C}_{1}$-values. The indicated $C_{1}$-value on the trend is showing that with very high values of $C_{1}$ the stress tends minimal. It is a definite method of influencing the stress levels in materials. It can be shown with Figure 5 that to obtain very minimal axial stresses in material, the wall thickness should be reduced. As is shown in the figure, the stress values are reducing as the wall thickness is reduced. Figure 6 shows that the Axial Stress Function increases with increased internal wall temperatures.

\section{Conclusions}

The work is very adequate in computing the thermal axial stress in combustors and cylindrical pipes at the instance of known wall surface temperatures. With the Non-dimensional consideration in the combustor axial Stress computation it is possible to indicate ways of minimizing the thermal axial stress in the material.

\section{References}

[1] G. N. Tret'yachenko, S. Karpinos and L. E. Kiyashko, "Thermal Stress State of Hollow Cylinders during Unilateral Internal Heating," UDC 539.319.624.074.4, 1976.

[2] I. J. Kumar and D. Rajgopalan, "Thermal Stresses in a Hollow Cylinder Due to a Sinusoidal Surface Heating Source," V. R. Thiruvenkatachar, F.N.I. Defence Science Laboratory, Delhi 6 I, 1969.

[3] K. Abrinia, H. Naee, F. Sadeghi and F. Djavanroodi, "New Analysis for the FGM Thick Cylinders under Combined Pressure and Temperature Loading," (C) 2008 Science Publications Tehran, Amirabad Shomali St., Tehran, Iran 852, 2008.

[4] S. Kubo, K. Uchida, T. Ishizaka and S. Ioka, "Determination of the Optimum Temperature History of Inlet Water for Minimizing Thermal Stresses in a Pipe by Multiphysics Inverse Analysis," Journal of Physics: Conference Series, Vol. 135, 2008, p. 012058.

[5] Y. Ootao, T. Akai and Y. Tanigawa, "Three-Dimensional 
Transient Thermal Stress Analysis of a Non-Homogeneous Hollow Circular Cylinder Due to a Moving Heat Source in the Axial Direction," Journal of Thermal Stresses, Vol. 18, No. 5, 1995, pp. 497-512.

[6] S. Fronius and G. Trankner, "Taschenbuch Maschinenbau,
Band 1/11 Grundlagen," 3rd Edition, VEB Verlag Technik, Berlin, 1975.

[7] E. Ufot, "Modeling Thermal Stresses in the Combustor of Gas Turbine," Ph.D. Dissertation, Rivers State University of Science and Technology, Port Harcourt, 2010. 